\title{
Estimation of energy consumption for rolling a mobile vehicle equipped with ultra-low-pressure tires
}

\author{
Vladimir Pryadkin ${ }^{1}$, Artyom Artyomov ${ }^{1, *}$, Pavel Kolyadin ${ }^{1}$, and Nikolay Bakach². \\ ${ }^{1}$ Voronezh State University of Forestry and Technologies named after G.F. Morozov, Department of \\ Automobiles and Service, Voronezh, Russian Federation \\ ${ }^{2}$ RUE SPC NAS of Belarus for Agricultural Mechanization, Minsk, Republic of Belarus
}

\begin{abstract}
The article deals with the problem of reducing energy consumption when moving mobile power sources on deformable support bases. On basis of experimental studies using test-bench equipment, the main output parameters of 1020x420-18 tire of Bel-79 model were determined. Analysis of the results obtained made it possible to determine an optimal range of intra-tire pressure, when the realized propulsive efficiency takes maximum values, and energy consumption for selfpropulsion is minimal.
\end{abstract}

\section{Introduction}

The use of wheel propellers with low intra-tire pressure in the structures of various mobile power sources for agricultural purposes is based on their high environmental compatibility when driven on waterlogged and weak soils.

Due to large overall dimensions and high relative deformation of such tires, a significant decrease in the values of contact pressures at the tire-soil border is provided and the track depth decreases after the passage of the wheel, resulting in the reduction of power losses for rolling and rutting. However, in the works of various scientific teams [1, 2] it was noted that with a decrease in the internal air pressure in the tire, there is a progressive increase in hysteresis losses, which in turn leads to an increase in power losses for wheel rolling. The problem of increasing the efficiency of agricultural vehicles equipped with ultra-lowpressure tires stands alongside the problem of increasing fuel efficiency. In [3], it is noted that when a highly elastic tire moves on deformable soil, there is a range of optimal intratire pressure, at which the total rolling resistance becomes minimal, and the propulsive efficiency takes maximum values. However, the issues of assessing the influence of operating modes of ultra-low-pressure tires on its energy consumption during rolling have not been studied enough.

Methods for determining the total resistance to movement of highly elastic tires based on the results of static bench tests aimed at studying the hysteresis losses in the tire, as well as physical and mechanical properties of soils, are of considerable interest [4-16], but they

\footnotetext{
*Corresponding author: artemow94@yandex.ru
} 
have not yet been sufficiently developed. Therefore, the most accurate way to obtain such data is to conduct experimental studies.

The aim of this work was to experimentally study the influence of the shape of the contact pressure diagram on the tire propulsive efficiency and the rolling resistance force on the deformable support base at different values of the tire load and tire pressure.

The object of research in this work was developed by Logus-agro LLC in conjunction with the Department of Automobiles and Service of Voronezh State University of Forestry and Technologies named after G.F. Morozov, the mobile power source MES-600, equipped with ultra-low-pressure tires 1020x420-18 [17]. To increase the efficiency of applying liquid mineral fertilizers in the early spring period, it is necessary to study the effect of the parameters of installed tires on energy consumption when driving across the field.

\section{Materials and methods}

Research aimed at studying energy consumption of ultra-low-pressure tires rolling on soil with low bearing capacity was carried out in laboratory conditions using test-bench equipment as well as measuring and recording equipment (Fig. 1). The experiment plan included a set of experiments aimed at obtaining such primary data as radial deformation of the tire $h_{z}$, track depth $h_{\Gamma p}$, rolling radius of the wheel $r_{k}$, value of the torque on wheel $M_{\kappa}$, tangential tractive force $P_{\kappa}$ and pressure distribution in the heel of contact $q$ at different vertical load $G_{Z}$ and tire inflation pressure $P_{w}$.

Based on technical characteristics of MES-600 [17], two modes of tire loading were determined: $3.93 \mathrm{kN}$ and $5.15 \mathrm{kN}$, corresponding to the load on the tire in the running state and at the technically permissible mass, respectively.

In the course of the experiment, the required air pressure $\mathrm{P}_{\mathrm{W}}$ was set in the tire and with the help of a movable carriage of the stand it was pressed against the support base with force $G_{z}$. Based on the data obtained in [18], for each value of the radial load, the optimal value of the traction force was determined, at which the tire implements the maximum propulsive efficiency. The traction load was created using a system of stacked weights connected to the movable table of the stand by a cable through a system of blocks. After each separate passage of the wheel, the soil was loosened and leveled.

The rolling resistance coefficient of a tire on soft soil is made up of two components, according to [4]:

$$
f=f_{u}+f_{z p}
$$

where $f_{ш}$ - rolling resistance coefficient of an elastic tire on a solid support; $f_{\text {гр }}$ - rolling resistance coefficient of a tire on soft soil.

The calculated determination of the values that make up expression (1) causes great difficulties, due to the complex description of the deformation process of thin rubber-cord casings and a deformable support base. 


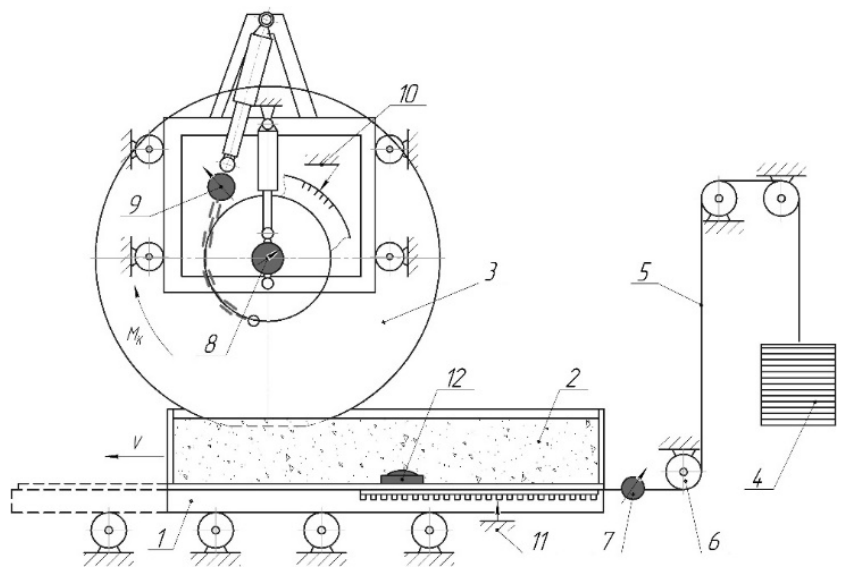

1 - movable stand table; 2 - box with soil background; 3 -1200x420-18 tire; 4 - traction load; 5 cable; 6 - block system; 7 - traction sensor; 8 - radial load sensor; 9 - torque sensor; 10 - inductive wheel angle sensor; 11 - inductive table movement sensor; 12 - membrane pressure sensor

Fig. 1. Measuring equipment layout.

In this regard, expression [10] was used to determine the total rolling resistance of the tire:

$$
F_{f}=\frac{R_{Z} \cdot e}{r_{k}},
$$

where $R_{z}$ - vertical reaction in contact of the tire with the ground; $r_{k}$ - kinematic wheel rolling radius; e - displacement of the vertical reaction relative to the center of the pressure diagram (distance from the geometric center of the diagram to the center of pressures P.C.).

The propulsive efficiency was determined from expression [7]:

$$
\eta_{\kappa}=P_{\kappa} \cdot r_{\kappa} / M_{\kappa}
$$

\section{Results and discussion}

The results of the tests carried out on a 1020x420-18 tire on a support base corresponding to the field prepared for sowing [17] are the dependences of the main output parameters of the tire depending on the internal air pressure and radial load, shown in Fig. 2-7 and in Table 1.

From the graph in Fig. 2 it can be seen that with an increase in the air pressure in the tire from 10 to $80 \mathrm{kPa}$, there is a progressive increase in static radius $r_{s t}$ and rolling radius $r_{k}$, and the static radius increases more sharply. This behavior of the tire can be caused by a decrease in the magnitude of its radial deflection, while at the same time by an increase in its slipping. For further calculations of rolling resistance moments of the tire, rolling radius $\mathrm{r}_{\mathrm{k}}$ is used.

Analysis of these dependencies in Fig. 3 shows that when the air pressure in the tire rises from 10 to $80 \mathrm{kPa}$ with a constant traction force Рк, torque $\mathrm{M}_{\kappa}$ changes, while a characteristic minimum of this dependence can be observed, which determines the presence of an optimal pressure range in terms of energy consumption for wheel rolling. 


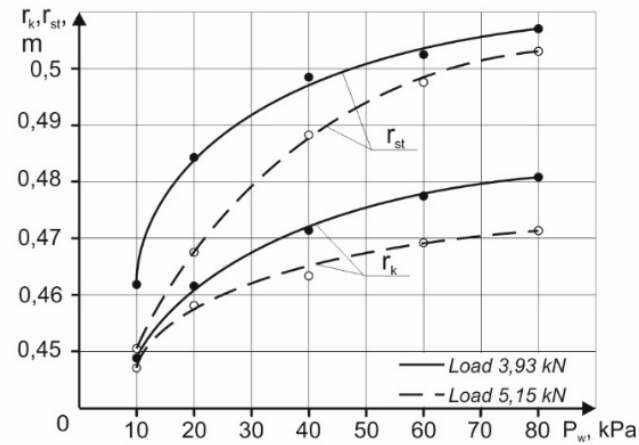

Fig. 2. Dependence of the wheel rolling radius on the air pressure in the tire.

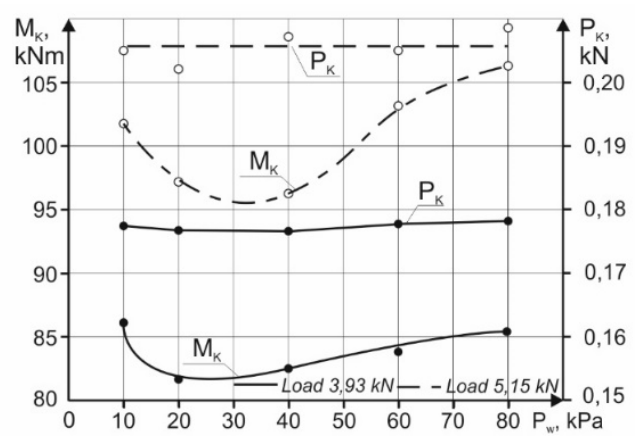

Fig. 3. Dependence of traction force and torque on the wheel on the air pressure in the tire.

Table 1. Experimental research results

\begin{tabular}{|c|c|c|c|c|c|c|c|c|c|c|}
\hline \multirow{2}{*}{$\begin{array}{l}\mathrm{P}_{\mathrm{W}}, \\
\mathrm{kPa}\end{array}$} & \multicolumn{5}{|c|}{ Load 3,93 kN } & \multicolumn{5}{|c|}{ Load 5,15 kN } \\
\hline & $\begin{array}{l}\mathrm{q}_{\max }, \\
\mathrm{kPa}\end{array}$ & $\begin{array}{c}\mathrm{M}_{\mathrm{K}} \\
\mathrm{kNm}\end{array}$ & $\begin{array}{l}\mathrm{P}_{\mathrm{K}}, \\
\mathrm{kN}\end{array}$ & $\mathrm{r}_{\mathrm{k}}, \mathrm{m}$ & $\begin{array}{c}\eta_{\max }, \\
\%\end{array}$ & $\begin{array}{l}\mathrm{q}_{\max }, \\
\mathrm{kPa}\end{array}$ & $\begin{array}{c}\mathrm{M}_{\mathrm{K}}, \\
\mathrm{kNm}\end{array}$ & $\begin{array}{l}\mathrm{P}_{\mathrm{K}}, \\
\mathrm{kN}\end{array}$ & $\mathrm{r}_{\mathrm{k}}, \mathrm{m}$ & $\begin{array}{c}\eta_{\max }, \\
\%\end{array}$ \\
\hline 10 & 23.2 & 86.06 & 0.1773 & 0.4489 & 0.843 & 31.3 & 101.79 & 0.2052 & 0.4478 & 0.846 \\
\hline 20 & 28.5 & 81.61 & 0.1766 & 0.4616 & 0.862 & 36.2 & 97.17 & 0.202 & 0.4582 & 0.867 \\
\hline 40 & 38.8 & 82.36 & 0.1764 & 0.4713 & 0.863 & 51.8 & 96.24 & 0.2072 & 0.4634 & 0.876 \\
\hline 60 & 44.3 & 83.75 & 0.1776 & 0.4775 & 0.858 & 64.5 & 103.19 & 0.2001 & 0.4692 & 0.857 \\
\hline 80 & 48.7 & 85.37 & 0.1781 & 0.4805 & 0.843 & 79.8 & 106.42 & 0.2085 & 0.4712 & 0.849 \\
\hline
\end{tabular}

Based on the obtained data on distribution of pressures in the zone of contact of the tire with the ground in the longitudinal plane of wheel rolling, an analysis was made of the change in the value of displacement of vertical reaction (P.C.) relative to the center of the pressure diagram ' 0 ' with an increase in the internal air pressure in the tire (Fig. 4-5).

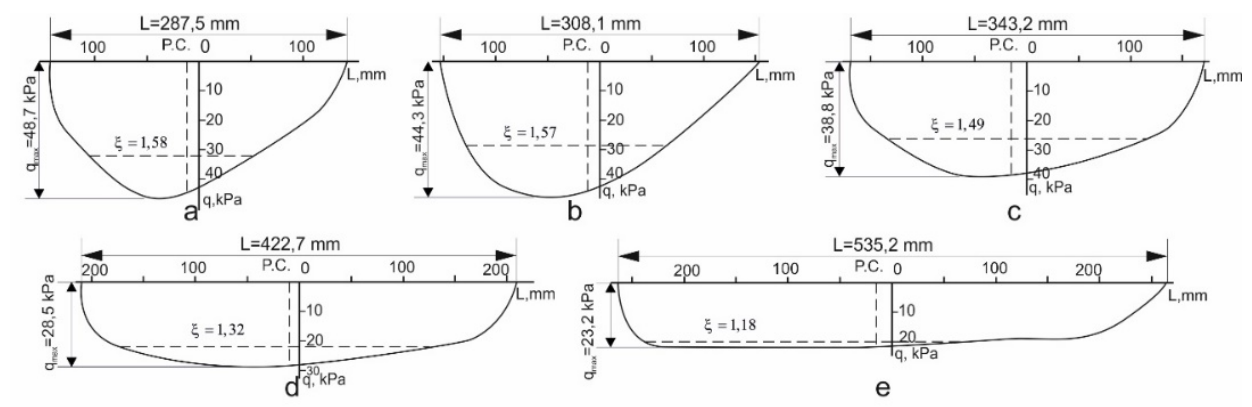

Fig. 4. The nature of the position change of the pressure center when air pressure in the tire changes and the load is $3.93 \mathrm{kN}$.

Using the obtained values, using formula (2), the rolling resistance forces of the tire were calculated at loads of 3.93 and $5.15 \mathrm{kN}$ (Fig. 6).

It can be seen from the graph in Fig. 6 that the rolling resistance force has a clear minimum in the pressure range of $20-30 \mathrm{kPa}$ at a load of $3.93 \mathrm{kN}$ and $30-40 \mathrm{kPa}$ at a load of $5.15 \mathrm{kN}$. Dependency analysis in Fig. 6 shows that the rolling resistance coefficient has a significant effect on the traction efficiency of a tire. In this pressure range, the tire also achieves maximum propulsive efficiency. Moreover, this range divides the chart into two zones. 
In the pressure range of $50-80 \mathrm{kPa}$, the rolling resistance force increases due to the increase in energy consumption for rutting. An increase in air pressure in the tire leads to a decrease in the tire-to-ground contact patch, an increase in the maximum contact pressures and, as a consequence, to a more pronounced immersion of the tire into the ground until the equilibrium of external forces and soil reactions in the contact zone occurs (Fig. 7).
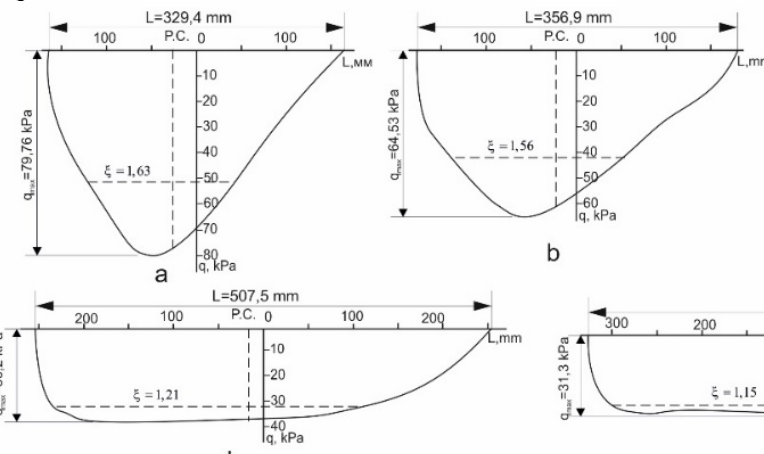

b
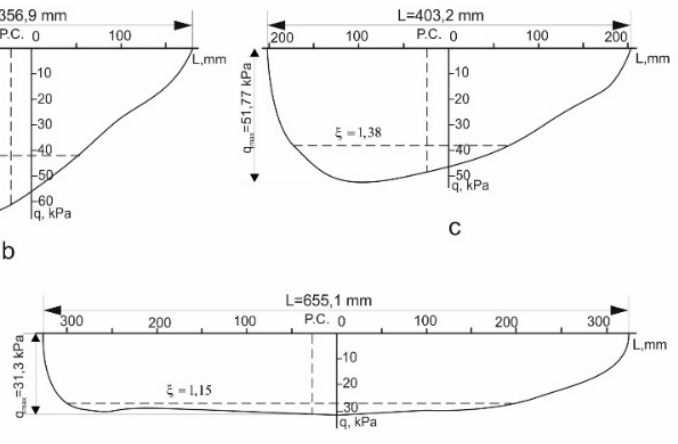

e

Fig. 5. Nature of the change in the position of the pressure center when the air pressure in the tire changes and the load is $5.15 \mathrm{kN}$.

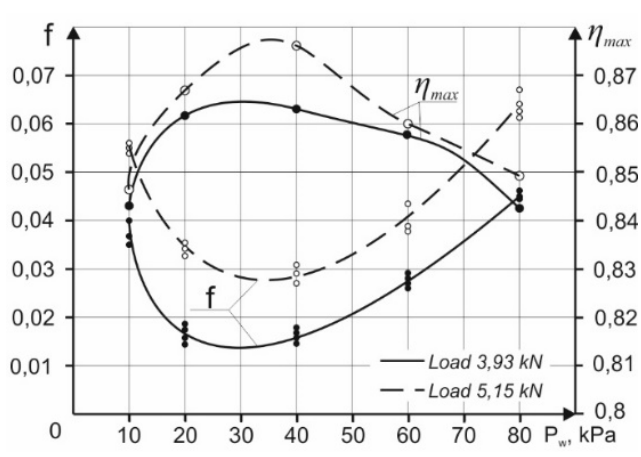

Fig. 6. Influence of air pressure in the tire on the rolling resistance coefficient and propulsive efficiency of the tire.

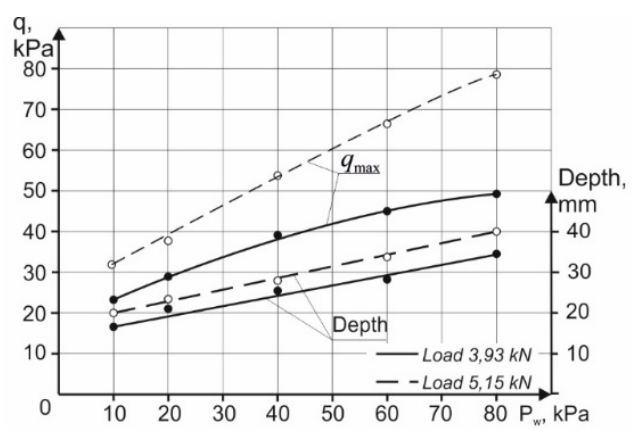

Fig. 7. Influence of air pressure in the tire on maximum contact pressures and track depth.

In the air pressure zone of $10-20 \mathrm{kPa}$, the rolling resistance force increases due to an increase in hysteresis losses (Fig. 8) and energy losses due to formation of folds on the tire sidewall (Fig. 9). This behavior of the tire can be confirmed by the data obtained in [19]. An increase in the load on the tire in this pressure range is highly undesirable, as it will lead to a decrease in the tire life.

To assess the passability of mobile power sources on ultra-low-pressure tires, in addition to rolling resistance forces, it is necessary to assess the values of the possible tractive effort on the traction wheels. Based on the assessment of the results of traction tests [9], Figure 10 shows a combined diagram of the reserve of tractive effort when the machine is moving on soft ground.

The area of the diagram enclosed between $\mu_{x}$ and $f$ dependences characterizes the possibility of movement under the given conditions. Analysis of the dependence of the difference between the coefficients of adhesion and rolling resistance $K_{D}$ makes it possible to estimate the value of the possible realizable specific tractive force when driving on soft ground.

When MES-600 moves without loading the hopper, a tire load of $3.93 \mathrm{kN}$ is realized, the optimum from the point of view of minimizing energy consumption is the range of air 
pressures in the tire from 20 to $30 \mathrm{kPa}$. With a coefficient of adhesion from 0.332 to 0.311 , the specific traction load reserve is from 0.302 to 0.278 .

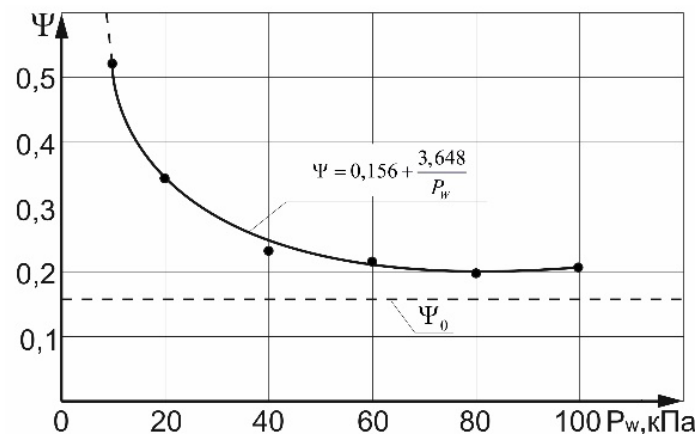

Fig. 8. Nature of the change in the hysteresis losses coefficient in 1020x420-18 tire.

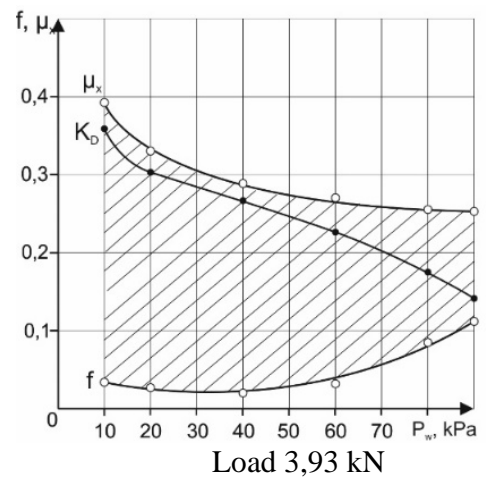

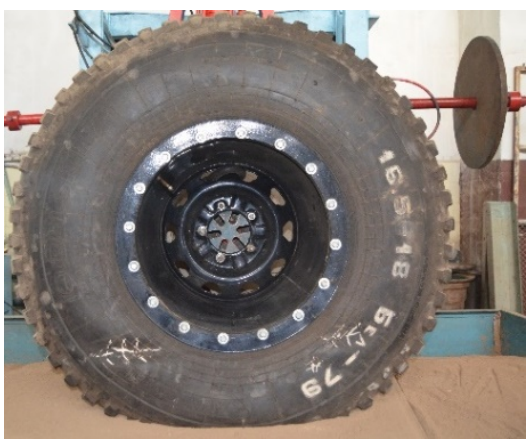

Fig. 9. Loss of shape of the sidewall of $1020 \times 420-18$ tire at an air pressure of 10 $\mathrm{kPa}$ and a load of $5.15 \mathrm{kN}$.

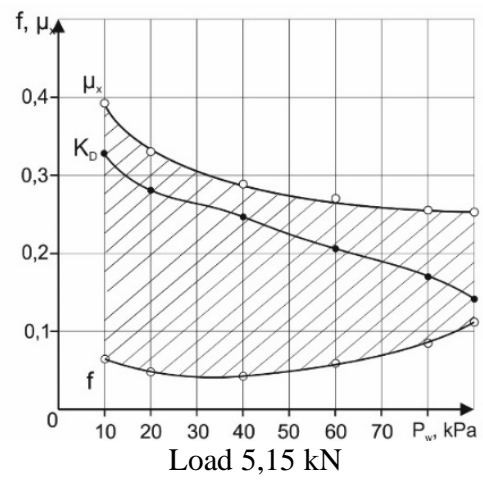

Fig. 10. Combined diagram of the traction reserve when the machine is moving on the ground.

When MES-600 hopper is fully loaded, in order to ensure the minimum rolling resistance, it is necessary to maintain the pressure in the range of $30-40 \mathrm{kPa}$. With a coefficient of adhesion on soft soil from 0.311 to 0.283 , the reserve of the specific traction load is from 0.267 to 0.253 .

As a result of the work carried out, it was found that when a mobile power source moves with installed ultra-low pressure tires on deformable soils, the amount of energy consumption is influenced not only by the internal air pressure in the tire, but also by the radial load on the wheel, while when driving on a solid support, the only determining factor is inflation pressure of the tire.

\section{Conclusions}

1. Experimental studies have established that when MES-600 mobile vehicle equipped with Bel-79 1020x420-18 ultra-low-pressure tires moves on weak soil in early spring, to ensure the minimum energy consumption for rolling, the intra-tire air pressure in the range from 20 to $40 \mathrm{kPa}$ is optimal.

2 It has been experimentally established that when the shape of the contact pressure diagram changes from parabolic to curved trapezoid, a Bel-79 1020x420-18 ultra-lowpressure tire implements the maximum propulsive efficiency of 0.862 at a load of $3.93 \mathrm{kN}$ 
and of 0.876 at a load of $5.15 \mathrm{kN}$. The conducted experiment has confirmed the previously put forward hypothesis in relation to 1300x600-533 tire with a 'slanting tree' tread [20].

3 A promising way to maintain the characteristics of tires in zones of minimum rolling resistance is introduction of systems for automatic regulation of air pressure in tires in the design of mobile devices, however, there are problems not only with the possibility of rapid inflation of large tires, but also with the choice of the control parameter.

\section{References}

1. H.D. Kutzbach, A. Bürger, S. Böttinger, J. Terramech. 82, 13-21 (2019)

2. S.D. Naranjo, C. Sandu, Saied Taheri, Shahyar Taheri, J. Terramech. 56, 119-137 (2014)

3. V.I. Pryadkin, Bulletin of the Voronezh State Technical University 4, 48-50 (2011)

4. C. Becker, S. Els, Journal of Terramechanics 88, 17-27 (2020)

5. F.E. Berisso, P. Schjønning, M. Lamande, P. Weisskopf, M. Stettler, T. Keller, Soil \& Tillage Research 131, 36-46 (2013)

6. T.R. Botha, P.S. Els, S.A. Shoop, C.M. Becker, A. Sopher, In: Proceedings of the 8th ISTVS Americas Regional Conference. (2016)

7. P. Farhadi, A. Golmohammadi, A. Sharifi, G. Shahgholi, J. Terramech. 78, 63-72 (2018)

8. A.G. Guthrie, T.R. Botha, P.S. Els, J. Terramech. 69, 13-21 (2017)

9. R. He, C. Sandu, E. Javier, J. E. Osorio, J. Terramech. 85, 59-76 (2019)

10. R. He, C. Sandu, A.K. Khan, A.G. Guthrie, P. Schalk Els, H.A. Hamersma, J. Terramech. 81, 3-22 (2019)

11. K. Nishiyama, H. Nakashima, H. Shimizu, J. Miyasaka, K. Ohdoi, J. Terramech. 74, 25-33 (2017)

12. P. Schjønning, M. Stettler, T. Keller, P. Lassen, M. Lamandé, Soil \& Tillage Research 152, 52-66 (2015)

13. H. Taghavifar, A. Mardani, J. Terramech. 50, 99-106 (2013)

14. H. Taghavifar, A. Mardani, Measurement 46, 4038-4044 (2013)

15. L. ten Damme, M. Stettler, F. Pinet, P. Vervaet, T. Keller, L.J. Munkholm, M. Lamandé, Soil \& Tillage Research 194 (2019)

16. L. ten Damme, M. Stettler, F. Pinet, P. Vervaet, T. Keller, L.J. Munkholm, M. Lamandé, Soil \& Tillage Research 204 (2020)

17. Z.A. Gojaev, S.V. Goncharenko, A.V. Artemov, V.I. Pryadkin, T.Z. Gojaev, Tractors and agricultural machines 3, 35-47 (2020)

18. S.V. Goncharenko, Z.A. Gojaev, A.V. Artemov, V.I. Pryadkin, T.Z. Gojaev, Tractors and agricultural machines 6, 50-58 (2020)

19. S.V. Goncharenko, Z.A. Gojaev, A.V. Artemov, V.I. Pryadkin, T.Z. Gojaev, Automotive industry 8, 18-21 (2020)

20. Z.A. Godzhaev, A. Yu. Izmailov, V.I. Pryadkin, Automotive industry 2, 9-12 (2015) 